\title{
Incidence and associated factors of residual neuromuscular block among patients underwent general anaesthesia at university of gondar hospital, a cross-sectional study
}

\begin{abstract}
Background: Residual neuromuscular block is a relatively common and often unrecognized complication of general anaesthesia in the post-anaesthesia care unit. Furthermore, it is the major contributing factor for patient's morbidity. The aim of this study was to assess the incidence and associated factors of residual neuromuscular block among patients underwent general anaesthesia at University of Gondar hospital
\end{abstract}

Methods: A hospital-based observational study was conducted from March 15 to April 30/2016. A total of 384 patients were included in the study. The presence/absence of residual neuromuscular block was assessed within the first 20minutes of PACU admission using double burst stimulation. Associated factors and sign symptoms of adverse respiratory events were also collected. Univariate analysis was performed descriptively using the Mann-Whitney U test for comparing Continuous variables. Chi-square test and Fishers exact test were used for comparing proportions. Bivariate and multivariate logistic regressions were used to identify associated factors.

Results: The overall incidence of residual neuromuscular block was found to be $12.9 \%$ The age of patient, being female (AOR=3.5, 95\% CI;1.789-6.857), intraoperative high cumulative dose of muscle relaxants ( $\mathrm{AOR}=1.23,95 \% \mathrm{CI} ; 1.12-1.35)$, and use of pancuronium $(\mathrm{AOR}=5.14,95 \% \mathrm{CI} ; 1.16-22.797)$ were factors associated with residual neuromuscular block. A total of 107(28.08\%) patients had ARE.

Conclusion and recommendation: residual neuromuscular block was a severe complication of general anaesthesia in the study patients. Adverse respiratory events are common in patients with residual neuromuscular block. We recommend use of intermediate acting muscle relaxants.

Keywords: residual neuromuscular block, adverse respiratory events, pancuronium, vecronium
Volume 7 Issue 6 - 2017

\author{
Hailu Yimer Tawuye, Ahmed Yimer, Habtamu \\ Getnet \\ Department of anaesthesia, school of medicine, college of \\ medicine and health sciences, University of Gondar, Gondar. \\ Ethiopia
}

Correspondence: Hailu Yimer Tawuye, Department of anaesthesia, school of medicine, college of medicine and health sciences, University of Gondar, Gondar, Ethiopia, Email hailuyimer.t@gmail.com

Received: April 20, 2017 | Published: April 27, 2017
Abbreviations: ARE, adverse respiratory events; ASA, american society of anesthesiologists; DBS, double burst stimulation; GA, general anaesthesia; NDMR, nondepolarizing neuromuscular blockers; NMBs, neuromuscular blockers; PACU, post anaesthesia care unit; PNS, peripheral nerve stimulator; RNMB, residual neuromuscular blocks; TOF, train of four; UOG, university of Gondar

\section{Background}

Incomplete recovery of the neuromuscular function also known as residual neuromuscular blockade (RNMB) is the most frequently observed complication in the post-anaesthesia care unit (PACU). The incidence is higher in developing than the developed countries. Residual neuromuscular blockage is the most common postoperative complication among patients undergoing surgical procedures under general anaesthesia; that is those who are taking non-depolarizing neuromuscular blocking drugs intraoperatively and there is a hug variability between individuals. ${ }^{1-4}$

RNMB among surgical patients operated under general anaesthesia can lead to potentially impaired recovery and produce adverse physiological effects. According to voluntary and clinical studies, RNMB may lead to impaired upper airway and respiratory muscle tone and coordination. Impaired airway and respiratory muscles function resulting from residual muscle paralysis may potentially increase the risk of aspiration, airway obstruction, hypoxia, difficulty coughing and breathing, impaired ventilation, and post-operative pulmonary complications. ${ }^{5-11}$ Although residual paralysis can occur at any post-operative recovery periods and for any patients after administration of non-depolarizing muscle relaxants, its incidence or severity and associated morbidity is variable and difficult to proof. This is mainly due to limited number of well-designed clinical studies, variables in clinical practice, and method of measurement of residual neuromuscular blockage used. anaesthetic used.

Despite the above factors, a study conducted in the very early years on RNMB had shown that the overall incidence of residual paralysis to be about $30 \%$ of post-operative patients arrive in recovery with TOF $<0.9,{ }^{12}$ this is incomparable with in 1970 s, the first paper on the topic, which estimated to be around $42 \%{ }^{13}$

The incidence of RNMB among patients who received a single intubating dose of non-depolarizing muscle relaxant was $45 \%$ ( TOF ratios $<0.9$ ) and $16 \%$ (TOF ratios $<0.7$ ). Even 2hours later, RNMB was observed, $37 \%$ of patients had TOF ratios $<0.9$ and $10 \%$ of had TOF ratios $<0.7 .{ }^{14}$ In another study in which neuromuscular blockade 
was not reversed, TOF ratios $<0.7$ were observed at admission to the PACU in $42 \%$ of patients who received vecuronium. ${ }^{16}$ A study by Hayes et al, reported that TOF ratios $<0.8$ were observed in $39 \%$ of subjects who received rocuronium, $64 \%$ of vecuronium, and $52 \%$ of atracurium group. ${ }^{15}$ In a recent meta-analysis, the incidence of RNMB was $12 \%$ (TOF $<0.7$ ) and $41 \%$ (TOF $<0.9$ ) when intermediate acting used, where as it was higher in patients who received long acting muscle relaxant $(35 \%$ and $72 \%$ when TOF $<0.7$ and $<0.9$ respectively). ${ }^{2}$ The incidence of RNMB was higher in long-acting non-depolarizing muscle relaxant than the intermediate acting.

Various reports have identified different factors to have association with the occurrence of postoperative residual neuromuscular blockage including age and gender of the patient, type and dose of muscle relaxant used, type and dose of reversal drug used, type of anaesthesia used intraoperatively, duration of surgery and anaesthesia, time of last dose given and reversed, presence of metabolic derangement, hypothermia, opioid and antibiotics given in the recovery. ${ }^{4,17-21}$ However, the reported magnitudes and associated factors may be different from developed to developing countries and have shown different time trends as the interplay between the various socioeconomics, clinical practice, and limited resources alter in sub-Saharan country setting. Therefore, the aim of this study was to determine the incidence and associated factors of RNMB among patients operated under general anaesthesia at University of Gondar Hospital, northeast Ethiopia.

\section{Methods}

A Hospital based cross-sectional study design was employed in University of Gondar Hospital, northwestern Ethiopia from March to April 2016. Those patients aged 18years and above who was operated under general anaesthesia with nondepolarizing muscle relaxants were included in the study. Those patients who were critically ill and intubated or need further oxygen supplement in recovery room, and those patients who were directly transferred to intensive care unit were excluded.

Patients with age group >18years who were operated under general anaesthesia with maintenance of inhalational anaesthetic and non-depolarizing muscle relaxant during the study period at the main surgical operation room were the study unit. Sample size was calculated using single population proportion formula by assuming the estimated incidence of residual neuromuscular blockade in the recovery room varies in various studies and it is not known in Ethiopia, therefore we take $50 \%$ as a maximal sample size, with $95 \%$ confidence interval, $5 \%$ absolute precision, the total sample size was calculated to be 384 .

$$
n=\frac{\left(Z_{\frac{a}{z}}\right)^{2} P(1-P)}{d^{2}}
$$

Where $\mathrm{n}=$ sample size, $\mathrm{p}=$ assumed incidence of residual paralysis, and $\mathrm{d}=$ assumed marginal error

The primary outcome measure was the occurrence of residual neuromuscular blockage, whereas adverse respiratory event and factors which contribute to the incidence of residual neuromuscular blockage were our secondary endpoints. In this particular study, RNMB was defined as presence of one or/ and two detectable visual or tactile fade in the response to peripheral nerve stimulation of the ulnar nerve for two consecutive 15 second separated double burst $\left(\mathrm{DBS}_{3,3}\right)$ stimulations.

Postoperatively within twenty minutes of recovery room admission neuromuscular function was assessed both with clinical parameters, mentioned above, and peripheral nerve stimulator $\left(\mathrm{EZstim}^{\mathrm{TM}} \mathrm{II}\right.$; Life-Tech R, Inc), accordingly: for each patient, the nerve stimulator equipment was checked for any error on the battery, its buttons, cables, and other possible problems and current adjusted at $80 \mathrm{~mA}$. The patients hand was cleaned with alcohol swap; air dried and positioned. Pregelled surface ECG electrodes placed. Then the negative electrode was firmly placed $1 \mathrm{~cm}$ proximal to the point at which the proximal flexion crease of the wrist crosses the radial side of the tendon to the flexor carpi ulnaris muscle. ${ }^{22}$ The positive electrode was attached proximal to the negative electrode at a distance of $3 \mathrm{~cm}$ parallel to the flexor carpi ulnaris over the surface of skin along the path of the ulnar nerve. Two consecutive double burst stimulations ( $\mathrm{DBS}_{3,3}$ ) separated with 15 seconds was performed and whether the presence or absence of detectable either visual or tactile fade in the response to the nerve stimulation was recorded. Three anaesthetist supervised by 3 supervisors collected the data.

First code was given to the completed questionnaire and then data were entered into SPSS version 20 statistical package for further analysis. Data cleaning were performed to check for accuracy and consistencies and missed values and variables. The results were presented in the form of tables, figures, and text. Both bivariate and multivariate logistic regressions were used to identify associated factors. Odds ratio with $95 \%$ confidence interval were used to identify the presence and strength of association and a $p$ value $<0.05$ was considered statistically significant.

Ethical clearance was obtained from ethical committee of school of medicine, collage of medicine and health sciences, University of Gondar. Written informed consent was obtained from each study subject after clear explanation what they would have to do take part in the research. Those patients who were identified as having pain during stimulation or critical problems associated with RNMB were get the appropriate treatment and oxygen support.

\section{Results}

\section{Socio-demographic characteristics of the participants}

Data were collected from a total of 384 patients, from these 381 patients were included in the final analysis. Three patients were excluded from the analysis because of incomplete data record. The majority of study participants were male $63.8 \%$. More than $29 \%$ of study subjects were in age group 26-35years. Two-hundred and eighty (73.5\%) of the participants were ASA physical status I (Table 1).

\section{Perioperative clinical characteristics and incidence of RNMB}

The overall incidence of residual neuromuscular block was found to be $49(12.9 \%)$ during the first 20 minutes of postoperative period in recovery room. This study showed that one hundred thirty-three $(34.91 \%)$ of patients were induced by ketopropofol (ketamine and propofol). Most $(83.2 \%)$ of patients did receive pancuronium as a maintenance for god surgical exposure. There was no patient who received narcotics in the recovery room during the time of data collection. However, intraoperatively Pethidine and fentanyl were administered in $29.92 \%$ and $36.22 \%$ of the patients respectively. Both fentanyl and Pethidine were provided for $16.54 \%$ of the subjects (Table 2). 
Table I Socio-demographic characteristics of study participants, at University of Gondar Hospital, Northwest Ethiopia, 2016 ( N=38I)

\begin{tabular}{|c|c|c|}
\hline Variables & No RNMB, n(\%) & RNMB, n(\%) \\
\hline \multicolumn{3}{|l|}{ Gender: } \\
\hline Male & $224(67.5)$ & $19(38.8)$ \\
\hline Female & $108(32.5)$ & $30(61.2)$ \\
\hline \multicolumn{3}{|l|}{ ASA: } \\
\hline I & $248(74.7)$ & $32(65.3)$ \\
\hline II & $7 I(2 I .4)$ & $13(26.5)$ \\
\hline III & $13(3.9)$ & $4(8.2)$ \\
\hline \multicolumn{3}{|l|}{ Age (years): } \\
\hline $18-25$ & $103(31.0)$ & $4(8.2)$ \\
\hline $26-35$ & $101(30.4)$ & $10(20.4)$ \\
\hline $36-50$ & $69(20.8)$ & $15(30.6)$ \\
\hline Above 50 & $59(17.8)$ & $20(40.8)$ \\
\hline $\mathrm{BMI}(\mathrm{kg} / \mathrm{m} 2)$ & $22.22+3.431$ & $21.46+2.90$ \\
\hline
\end{tabular}

Data are presented as $\mathrm{n}(\%)$, and mean $\pm \mathrm{SD}$

Table 2 Perioperative anaesthetic and surgical parameters of study participants, at University of Gondar Hospital, Northwest Ethiopia, 2016 $(\mathrm{N}=38 \mathrm{I})$

\begin{tabular}{lll}
\hline Parameters & No RNMB, n(\%) & RNMB, n(\%) \\
\hline Urgency: & & \\
Emergency & $256(77.1)$ & $32(65.3)$ \\
Elective & $76(22.9)$ & $17(34.7)$ \\
Induction used: & & \\
Propofol & $98(29.5)$ & $20(40.8)$ \\
Ketamine & $91(27.4)$ & $13(26.5)$ \\
Thiopental & $24(7.2)$ & $2(4.1)$ \\
Ketopropofol & $119(35.8)$ & $14(28.6)$ \\
Opioid Analgesics used: & & \\
Pethidine & $105(31.6)$ & $9(18.4)$ \\
$\begin{array}{l}\text { Fentanyl } \\
\text { Pethidine and fentanyl }\end{array}$ & $113(34.0)$ & $25(51.0)$ \\
None & $53(16.0)$ & $10(20.4)$ \\
Procedure: & $61(18.6)$ & $5(10.2)$ \\
Abdominal & & $24(49.0)$ \\
\hline
\end{tabular}

\begin{tabular}{|c|c|c|}
\hline Parameters & No RNMB, n(\%) & RNMB, n(\%) \\
\hline Non-abdominal & $165(49.7)$ & $25(5 \mid .0)$ \\
\hline \multicolumn{3}{|l|}{ Types of NDMR used: } \\
\hline Pancuronium & $270(81.3)$ & $47(96.0)$ \\
\hline Vecuronium & $62(18.7)$ & $2(4.0)$ \\
\hline NDMR Dose, $(\mathrm{mcg} / \mathrm{kg})^{*}$ & II $3.5(85-158)$ & $115(97-190)$ \\
\hline Last dose to reversal(min)* & $50(30.75-70)$ & $35(27-55)$ \\
\hline Duration of anaesthesia $(\mathrm{min})^{*}$ & I I $3.5(85-158)$ & II 5 (97-190) \\
\hline
\end{tabular}

*median (IQR)

\section{Factors associated with RNMB}

Types of analgesic used, the time interval between last NDMR dose administration and DBS measurement; and last NDMR dose time to neostigmine administration time was significant in the univariate analysis, but not significant and fail to appear into the final multivariate logistic regression model. Multiple regression analysis indicated that gender, age, higher amount of intraoperative NDMR dose, and use of pancuronium were associated factors for the development of RNMB. For a $1 \mathrm{mcg} / \mathrm{kg}$ increase in cumulative intraoperative dose of non-depolarizing neuromuscular blocking drugs, there was 1.23 times increased risk of developing inadequate reversal of neuromuscular blockage in patients operated under general anaesthesia $(\mathrm{AOR}=1.23,95 \% \mathrm{CI}: 1.12-1.356)$. The study revealed that incidence of inadequate reversal of neuromuscular blockage was higher among female patients when compared to that of males $(\mathrm{AOR}=3.5,95 \%$ CI: 1.789-6.857) (Table 3).

\section{Adverse respiratory events}

Out of 381 patients, $107(28.1 \%)$ of patients were developed adverse respiratory events (which is defined as the occurrence of one or more respiratory complications). From 107 of patients who were developed one or more adverse respiratory events, 56(52.3\%) of patients were in the residual paralysis groups. The number of patients developing postoperative difficulty of deep breathing was significantly higher in the residual block than patients who were fully reversed (26 and 18 patients, respectively) (Table 4).

Table 3 Factors associated with residual neuromuscular blockage among patients operated under general anaesthesia with non-depolarizing muscle relaxant at University of Gondar Hospital, Northwest Ethiopia, $2016(\mathrm{~N}=38 \mathrm{I})$

\begin{tabular}{|c|c|c|c|c|}
\hline Variables & RNMB & No RNMB & Crude OR $(95 \% \mathrm{CI})$ & Adjusted OR (95\% Cl) \\
\hline \multicolumn{5}{|l|}{ Gender } \\
\hline Male & 19 & 224 & I & $I^{*}$ \\
\hline Female & 30 & 108 & $3.275(I .764-6.08 I)$ & $3.5(1.789-6.857)$ \\
\hline \multicolumn{5}{|l|}{ Age (years) } \\
\hline $18-25$ & 4 & 103 & I & $I^{*}$ \\
\hline $26-35$ & 10 & 101 & $2.550 / 0.774-8.394$ & $2.27(0.66-7.822)$ \\
\hline $36-50$ & 15 & 69 & $5.598 / 1.78-17.57$ & $3.86(1.16-12.811)$ \\
\hline Above 50 & 20 & 59 & $8.729 / 2.85-26.758$ & $7.32(2.29-23.392)$ \\
\hline \multicolumn{5}{|c|}{ Types of NDMR used: } \\
\hline Vecronium & 2 & 62 & 1 & $I^{*}$ \\
\hline Pancuronium & 47 & 270 & $5.396 / 1.28-22.816$ & $5.14 / 1.16-22.797$ \\
\hline \multicolumn{4}{|c|}{ NDMR Dose (mcg kg) } & $I^{*}$ \\
\hline median (IQR) & $108(90-136)$ & $87(67-\mid 15)$ & I. 190 / I.098-I.290 & $1.23 / 1.12-1.356$ \\
\hline
\end{tabular}

*Significant from the multivariate logistic regression 
Table 4 Adverse respiratory events associated with residual neuromuscular blockage among patients operated under general anaesthesia with nondepolarizing muscle relaxant at University of Gondar Hospital, Northwest Ethiopia, $2016(\mathrm{~N}=38 \mathrm{I})$

\begin{tabular}{llll}
\hline Variables & RNMB & $\begin{array}{l}\text { No } \\
\text { RNMB }\end{array}$ & P-value \\
\hline $\begin{array}{l}\text { Hypoxia: } \\
\text { Mild }\end{array}$ & 6 & 26 & $* *$ \\
Moderate to severe & 7 & 28 & \\
Moderate to severe & 7 & 28 & \\
Signs of upper airway obstruction & 2 & 0 & 0.016 \\
Inability to breathe deeply & 26 & 18 & 0 \\
Signs of respiratory muscle weakness & 14 & 3 & 0 \\
The need for airway support & I & I & $* *$ \\
\hline
\end{tabular}

Data was presented in $\mathrm{n}$ (number)

** not Significant

\section{Discussion}

In this study, a total incidence of residual paralysis was found to be $12.9 \%$ among patients who underwent different surgical procedures under general anaesthesia maintained with non-depolarizing neuromuscular blocking agents within the first 20minutes of postoperative recovery room arrival. This finding is in agreement with findings by Naguib $\mathrm{M}$ et al., ${ }^{23}$ and Kim et al., ${ }^{24}$ which was $12 \%$ and $14.7 \%$ with $\mathrm{TOF}<0.7$, respectively. The incidence in the current study was lower than the studies done by Murphy et al (88\%), ${ }^{25}$ Hayes et al., ${ }^{26}$ (64\%), and Baillard et al. ${ }^{27}$ (42\%), but it was higher than a study done by Baillard et al., ${ }^{28}(9 \%)$. The incidence varies widely among studies, the reason may be due to the difference in study design, types of muscle relaxant used, definition and method used to measure. In addition, other perioperative clinical factors may affect the incidence. We have used simple peripheral nerve stimulator to assess RNMB and it is hard to compare it with the results of other studies done using qualitative measurements. However, it has been reported that DBS enables clinicians to detect minimal residual block, (TOF up to 0.6).

\section{Factors associated with RNMB}

Various studies have pointed out multiple potential factors associated with the incidence of residual neuromuscular blocking drugs. ${ }^{17-21,29,30}$ Gender and age of the patents, total dose of relaxant administered and type of relaxant used were found, in multiple-logistic regression model, factors associated with the occurrence of residual block. Sex of the patients was significantly associated with residual paralysis in this study. Female were 3.5 more likely to develop RNMB when compared to men (AOR=3.5, 95\% CI: 1.789-6.857. This finding was in agreement with other studies. ${ }^{29,30}$ This might be due to the fact that physiological difference between men and women. Women were more sensitive to muscle relaxant than men, and in order to achieve the same level of neuromuscular block as men. Women have much amount of fat tissue and less muscle mass relative to men and this may decrease the volume of distribution and lead to an increased plasma concentration of muscle relaxants. Other reason may be due to lower levels of total protein and albumin in women plasma.

In this study the age of the patients was independently associated with the development of RNMB. Elderly patients (>50years) were 7.3 times more likely to have residual paralysis than younger patients (AOR=7.32, 95\% CI: 2.29-23.392). The explanation for this may be due to the reduction in metabolism and excretion of neuromuscular blocking agents, which leads to prolonged effect of muscle relaxant drugs in elderly. Our finding is in line with other study, which shows the incidence of RNMB was increased up to $65 \%$, in older patients who received vecuronium. ${ }^{15}$ A study done by Murphy and his colleagues reported that the incidence of RNMB was higher in elderly (70-90years) than young patients $\left(57.7 \%\right.$ and $30 \%$ respectively). ${ }^{17}$ In an investigation that compared incidence of RNMB between elderly and young patients, $44 \%$ of elderly patients had RNMB than only $20 \%$ in the young. ${ }^{18}$

Type of muscle relaxant used was significantly associated with the occurrence of RNMB in this study. Patients who was received longacting muscle relaxant (pancuronium) showed a 5-fold increased risk of developing RNMB in this study. Our study was comparable with different studies. ${ }^{2,19,20,31}$

Higher cumulative doses of muscle relaxant contribute a lot for development of residual paralysis in early postoperative period. For a unite increase in dose, there was a 1.23 times increased risk of developing RNMB (AOR=1.23, 95\% CI: 1.12-1.356). The finding was in agreement with other studies. ${ }^{16,21}$

The effect of RNMB on adverse respiratory events has been demonstrated in several studies. Our finding shows that from a total of 56 patients with ARE in the residual paralysis group, Inability to breathe deeply was observed in twenty-six patients and fourteen of patients were developed sign and symptom of respiratory muscle weakness. In Germany a study by Bissinger et al., ${ }^{31}$ the rate of hypoxemia and hypercarbia were more common, $60 \%$ in patients who received pancuronium and developed postoperative residual paralysis. ${ }^{31}$

Another observational investigation had reported that $73.8 \%$ of ARE patients had TOF $<0.7$ in the post anesthesia care unit. According to the above study report, among the AREs the rate of severe hypoxemia was $59.0 \%$, upper airway obstruction (34.4\%), and mild hypoxemia (19.7\%). Similarly, Other respiratory complications observed was inability to breathe deeply (11.5\%), symptoms of respiratory muscle weakness $(9.0 \%)$, signs of respiratory distress $(8.2 \%)$, and reintubation $(6.2 \%)$ were more serious complication of inadequate reversal. ${ }^{32}$ In our study the incidence of AREs were very high when compared to previous studies. This might be due to poor recovery room setup. Unlike most other investigations, Oxygen support through 3L nasal cannula was not provided to our patients. Since the causes and types of adverse respiratory events in postoperative patients are multi-factorial, we recognize the inability of this study to identify the specific types and specific causes of adverse respiratory events as a limitation.

The limitation of this study was subjective measurement of the neuromuscular function, using simple peripheral nerve stimulator, to assess RNMB because of the limited resource. This might decrease the actual incidence and severity of RNMB. Some factors like postoperative temperature were not included due to limited time as well as resource. Gynaecologic and obstetric patients were not included.

\section{Conclusion}

The results of our study demonstrated that RNMB was common in our institution recovery room. The use of pancuronium, high intraoperative dose, age and gender were the most important determinant factors of RNMB. Adverse respiratory events were most frequent in patients who had residual neuromuscular block. 


\section{Declaration}

\section{Consent}

Written informed consent was obtained from the patient's preoperatively for data collection and the publication of this report.

\section{Competing interest}

We all authors (Hailu Yimer, Ahmed Yimer, and Habtamu Getnet) declare that, we did not have any financial or non-financial competing interests.

\section{Funding}

This research was supported by university of Gondar.

\section{Authors' contribution}

$\mathrm{HY}$ is the corresponding author and made substantial contributions in conception and design, acquisition of data, analysis and interpretation of data and has been involved in drafting the manuscript. AY Participated in the design of the study and performed the statistical analysis and interpretation. HG Participated in the design of the study, writing of results and discussion and has been involved in drafting the manuscript. All authors read and approved the final manuscript. HY write the manuscript.

\section{Acknowledgements}

We would like to thank University of Gondar for approval of ethical clearance and technical support for this study. We also acknowledge all staff of department of anaesthesia for their help and courage. Above all our heartfelt thanks go to study participants. All data collectors and the supervisors are highly acknowledged for the utmost effort they put to the quality of this research. This research was made possible by the support of the of university of Gondar.

\section{Consent for publication}

\section{Not applicable}

Ethics approval and consent to participate. Ethical clearance was obtained from ethical committee of school of medicine, collage of medicine and health sciences, University of Gondar. Written informed consent was obtained from each study subject after clear explanation what they would have to do take part in the research.

\section{Availability of data and materials section}

The datasets used and/or analyzed during the current study available from the corresponding author on reasonable request.

\section{References}

1. Mathias LA, de Bernardis RC. Postoperative residual paralysis. Revista brasileira de anestesiologia 62(3): 439-450. Naguib M, Kopman AF, Ensor JE (2007) Neuromuscular monitoring and postoperative residual curarisation: a meta-analysis. Br J Anaesth. 2012;98(3):302-316.

2. Murphy GS, Szokol JW, Avram MJ, et al. Postoperative residual neuromuscular blockade is associated with impaired clinical recovery. Anesth Analg. 2013;117(1):133-141.

3. Murphy GS, Brull SJ. Residual neuromuscular block: lessons unlearned Part I: definitions, incidence, and adverse physiologic effects of residual neuromuscular block. Anesth Analg. 2010;111(1):120-128.

4. Berg H, Roed J, Viby-Mogensen J, et al. Residual neuromuscular block is a risk factor for postoperative pulmonary complications. A prospective, randomized, and blinded study of postoperative pulmonary complications after atracurium, vecuronium and pancuronium. Acta Anaesthesiol Scand. 1997;41(9):1095-1103.

5. Murphy GS, Szokol JW, Marymont JH, et al. Intraoperative acceleromyographic monitoring reduces the risk of residual neuromuscular blockade and adverse respiratory events in the postanesthesia care unit. Anesthesiology. 2008;109(3):389-398.

6. Murphy GS, Szokol JW, Marymont JH, et al. Residual neuromuscular blockade and critical respiratory events in the postanesthesia care unit. Anesth Analg. 2008;107(1):130-137

7. Sundman E, Witt H, Olsson R, et al. The incidence and mechanisms of pharyngeal and upper esophageal dysfunction in partially paralyzed humans. Pharyngeal video radiography and simultaneous manometry after atracurium. Anesthesiology. 2000;92(4):977-984.

8. Eriksson LI, Sundman E, Olsson R, et al. Functional assessment of the pharynx at rest and during swallowing in partially paralyzed humans: simultaneous videomanometry and mechanomyography of awake human volunteers. Anesthesiology. 1997;87(5):1035-1043.

9. Eikermann M, Vogt FM, Herbstreit F, et al. The predisposition to inspiratory upper airway collapse during partial neuromuscular blockade. Am J Respir Crit Care Med. 2007;175(1):9-15.

10. Murphy GS, Szokol JW, Franklin M, et al. Postanesthesia care unit recovery times and neuromuscular blocking drugs: a prospective study of orthopedic surgical patients randomized to receive pancuronium or rocuronium. Anesth Analg. 2004;98(1):193-200.

11. Murphy GS, Szokol JW, Marymont JH, et al. Intraoperative acceleromyographic monitoring reduces the risk of residual neuromuscular blockade and adverse respiratory events in the postanesthesia care unit. Anesthesiology. 2008;109(3):389-398.

12. Viby-Mogensen J, Jorgensen B, Ording H. Residual curarization in the recovery room. Anesthesiology. 1979;50(6):539-541.

13. Debaene B, Plaud B, Dilly MP, et al.Residual paralysis in the PACU after a single intubating dose of nondepolarizing muscle relaxant with an intermediate duration of action. Anesthesiology. 2003;98(5):1042-1048.

14. Hayes AH, Mirakhur RK, Breslin DS, et al. Postoperative residual block after intermediate-acting neuromuscular blocking drugs. Anaesthesia . 2001;56(4):312-318.

15. Baillard C, Gehan G, Reboul-Marty J, et al. Residual curarization in the recovery room after vecuronium. Br J Anaesth. 2000;84(3):394-395.

16. Murphy GS, Szokol JW, Avram MJ, et al. Residual Neuromuscular Block in the Elderly: Incidence and Clinical Implications. Anesthesiology. 2015;123(6):1322-1336.

17. Pietraszewski P, Gaszynski T. Residual neuromuscular block in elderly patients after surgical procedures under general anaesthesia with rocuronium. Anaesthesiol intensive ther. 2013;45(2):77-81.

18. Murphy GS, Szokol JW, Marymont JH, et al. Recovery of neuromuscular function after cardiac surgery: pancuronium versus rocuronium. Anesth Analg . 2013;96(5):1301-1307.

19. Bevan DR, Smith CE, Donati F. Postoperative neuromuscular blockade: a comparison between atracurium, vecuronium, and pancuronium. Anesthesiology. 1988; 69(2):272-276.

20. Slavov V, Khalil M, Merle JC, et al. Comparison of duration of neuromuscular blocking effect of atracurium and vecuronium in young and elderly patients. Br J Anaesth. 1995;74(6):709-711.

21. Viby-Mogensen J. Neuromuscular monitoring. Current opinion in anaesthesiology .2001;14(6):655-659.

22. Naguib M, Kopman AF, Ensor JE. Neuromuscular monitoring and postoperative residual curarisation: a meta-analysis. $B J A$ 2007;98(3):302-316. 
23. Kim KS, Lew SH, Cho HY, et al. Residual paralysis induced by either vecuronium or rocuronium after reversal with pyridostigmine. Anesth Analg . 2002;95(6):1656-1660.

24. Murphy GS, Szokol JW, Marymont JH, et al. Residual paralysis at the time of tracheal extubation. Anesth Analg. 2005;100(6):1840-1845.

25. Hayes AH, Mirakhur RK, Breslin DS, et al. Postoperative residual block after intermediate-acting neuromuscular blocking drugs. Anaesthesia. 2011;56(4):312-318.

26. Baillard C, Gehan G, Reboul-Marty J, et al. Residual curarization in the recovery room after vecuronium. Br J Anaesth. 2000;84(3):394-395.

27. Baillard C, Clec'h C, Catineau J, et al. Postoperative residual neuromuscular block: a survey of management. $\mathrm{Br} J$ Anaesth. 2005;95(5):622-626.
28. Semple P, Hope DA, Clyburn P, et al. Relative potency of vecuronium in male and female patients in Britain and Australia. $\mathrm{Br} J$ Anaesth. 1994;72(2):190-194.

29. Xue FS, Liao X, Liu JH, et al. Dose response curve and time-course of effect of vecuronium in male and female patients. Br J Anaesth. 1998;80(6):720-724.

30. Bissinger U, Schimek F, Lenz G . Postoperative residual paralysis and respiratory status: a comparative study of pancuronium and vecuronium. Physiol Res. 2000;49(4):455-462.

31. Murphy GS, Szokol JW, Marymont JH, et al. Residual neuromuscular blockade and critical respiratory events in the postanesthesia care unit. Anesth Analg. 2008;107(1):130-137. 